\title{
Long-term survival of carotid stenting patients with regard to single- or double-vessel carotid artery disease: a propensity score matching analysis
}

Josef Veselka, Petr Hajek, Cyril Štěchovský, Martin Horváth, Radka Adlová, Robert Roland, Ingrid Homolová, Eva Hansvenclová, Petra Zimolová

Department of Cardiology, $2^{\text {nd }}$ Medical School, Charles University, University Hospital Motol, Prague, Czech Republic

Submitted: 3 April 2020; Accepted: 18 July 2020

Online publication: 17.08 .2020

Arch Med Sci 2021; 17 (4): 849-855

DOI: https://doi.org/10.5114/aoms.2020.98167

Copyright $\odot 2020$ Termedia \& Banach

\section{Abstract}

Introduction: There is lack of long-term data outside of controlled clinical trials in carotid artery stenting (CAS). In this study, we compared the shortterm outcome, long-term survival, and rate of re-interventions for restenosis in patients after CAS, related to the extent of carotid atherosclerosis classified as single-vessel (unilateral) or double-vessel (bilateral) carotid artery disease.

Material and methods: We retrospectively evaluated 599 patients with significant carotid artery stenosis, who underwent 763 CAS procedures, and used the propensity score to match 226 pairs (452 patients) in the single- or double-vessel carotid disease.

Results: There was no significant difference in the occurrence of in-hospital major adverse events (3.5\% vs. $3.1 \%$ of patients in the double-vessel carotid group vs. the single-vessel carotid group; $p=1$ ) The mean follow-up was $6.1 \pm 4.0$ years, and a total of $181(40 \%)$ deaths occurred during 2759 patient-years, which translates into 7.8 and 5.3 deaths per 100 patient-years in the double-vessel carotid group and the single-vessel carotid group, respectively $(p<0.01)$. The survival in the double-vessel carotid group vs. the single-vessel carotid group at 10 years was $46 \%$ (95\% Cl: $38-54 \%$ ) vs. $55 \%$ (95\% Cl: 47-63\%) $(p<0.01)$. Twenty-four (11\%) patients and $6(3 \%)$ patients underwent re-interventions for restenosis in the double-vessel and the single-vessel carotid disease group, respectively $(p<0.01)$.

Conclusions: Patients with CAS and significant double-vessel carotid artery disease had similar peri-procedural risk, but had a worse long-term survival, and a higher rate of re-interventions for restenosis compared to the single-vessel carotid artery disease patients.

Key words: carotid artery disease, stenting, survival.

\section{Introduction}

Forty-five years ago, Doctors Burggraf and Parker described the clinical course of patients with coronary artery disease related to their angiographically-determined severity [1]. They showed that patients with single-, double-, or triple-vessel disease have entirely different long-term survival rates. Subsequently, this classification of coronary artery disease has become a part of basic knowledge in cardiology textbooks.

\author{
Corresponding author: \\ Prof. Josef Veselka \\ Department \\ of Cardiology \\ $2^{\text {nd }}$ Medical School \\ Charles University \\ University Hospital Motol \\ Prague, Czech Republic \\ Phone: +42224434900 \\ E-mail: veselka.josef@ \\ seznam.cz
}


Based on 1-year data published in the past [2], we hypothesised that patients with double-vessel carotid artery disease (carotid artery disease with symptomatic internal/common carotid artery stenosis $\geq 50 \%$ or asymptomatic stenosis $\geq 70 \%$, and contralateral stenosis of the internal or common carotid artery $\geq 50 \%$ ) have worse long-term survival than patients with single-vessel carotid disease (unilateral carotid artery disease $\geq 50 \%$ for symptomatic or $\geq 70 \%$ for asymptomatic patients).

In this study, we report the short-term outcome, long-term survival, and rate of re-interventions for restenosis in patients after carotid artery stenting (CAS) related to the extent of carotid atherosclerosis classified as single-vessel (unilateral) or double-vessel (bilateral) carotid artery disease.

\section{Material and methods}

We retrospectively evaluated data that had been collected prospectively from a single-centre institutional registry of 599 patients with significant carotid artery stenosis, who underwent 763 CAS procedures between 2005 and 2019 and were enrolled in this study. Some of the patients were included in previous reports [2-5].

\section{Patient assessment, procedure, and follow-up}

The severity of the stenosis was assessed by Duplex ultrasound performed within 2 days prior to the procedure and, if necessary, confirmed by CT angiography. Patients were considered for endovascular revascularisation in the presence of $\geq 70 \%$ asymptomatic or $\geq 50 \%$ symptomatic stenosis of the internal and/or common carotid artery [6].

All patients provided their written informed consent before the CAS procedure.

All CAS procedures were performed by experienced interventional cardiologists after a detailed multidisciplinary evaluation as well as a discussion with the patient and/or his/her family and according to the current guidelines [7-9]. The procedural technique details were published previously $[2,3]$.

The selection of stents and embolic protection systems was performed at the operator's discretion. The majority of procedures were performed via the femoral approach using 7 or $8 \mathrm{Fr}$ guiding catheter or $6 \mathrm{Fr}$ guiding sheath. After CAS, all patients were repeatedly examined by nursing staff and physicians (including neurological examination), and all symptomatic patients were examined by board-certified neurologists. Post-procedural intracranial evaluation with magnetic resonance imaging or computed tomography was performed if the neurological status of the patient had changed. Asymptomatic patients after uncomplicated procedures were discharged the next day.
Angiology specialists performed the clinical and ultrasound follow-up at 1 month and 12 months after CAS, and annually thereafter. All patients were treated with two antiplatelet agents for 1 or more months, and aspirin indefinitely. Statins were prescribed to all patients. The indication for repeated interventions was at the discretion of each participating angiologist and interventionalist.

The survival of patients was checked in the National Database of Deaths.

\section{Definitions, study design, and endpoints}

Early major adverse events consisted of minor stroke, major stroke, myocardial infarction, and death. Stroke was defined as a neurological deficit that persisted for more than $24 \mathrm{~h}$; minor stroke was defined as a new neurological deficit that resolved completely or returned to baseline within 30 days; and major stroke was defined as a neurological deficit that did not resolve within 30 days. Myocardial infarction was defined as the appearance of new pathologic $Q$ waves on a standard electrocardiogram in two or more leads and significant release of troponin above the upper limit of normal.

We divided the patients in two matched groups - with single-vessel carotid disease or double-vessel carotid disease - for whom we assessed the long-term survival as the primary endpoint and the in-hospital rate of adverse cardiovascular events and re-interventions for restenosis as the secondary endpoints.

This study was conducted in accordance with the Declaration of Helsinki principles and was approved by the Institutional Ethical Committee.

\section{Statistical analysis}

Two experienced statisticians edited and evaluated the data, which are presented as means \pm SD or median and interquartile range (IQR) or counts and proportions. Student's t-test or Mann-Whitney test were used to evaluate the difference between continuous variables, and the Fisher's exact test was used between categorical variables. The data distribution was evaluated by the Kolmogorov-Smirnov test. Kaplan-Meier survival analysis was used to estimate survival with $95 \%$ confidence intervals.

Given the inherent differences between patients with single-vessel carotid disease and double-vessel carotid disease, we calculated a propensity score for the following variables:

- sex, age, smoking, renal failure, diabetes, hypertension, cerebral ischaemic symptoms in the last 6 months, previous coronary revascularisation (percutaneous or surgical), and previous myocardial infarction. The propensity score was estimat- 
ed using a logit model. Matching was performed using the $1: 1$ nearest neighbour method without replacement, which yielded 226 subjects with single-vessel carotid disease matched with 226 subjects with double-vessel carotid disease. $P<0.05$ was considered statistically significant. All reported $p$ values were two-sided. The software GraphPad (release 6.05, GraphPad Software Inc., La Jolla, California, USA) was used for statistical analysis.

\section{Results}

A total of 599 consecutive patients who underwent 763 CAS were enrolled. We identified 244 (41\%) patients with double-vessel carotid disease and compared them with 355 (59\%) patients with single-vessel carotid disease (Tables I-III).

The matched cohort comprised 452 (75\%) patients (226 in the single-carotid disease group and 226 patients in the double-vessel carotid disease group) (Tables I-III).

Patients in the matched double-vessel carotid disease group needed more contrast medium during the procedure, were treated with shorter stents, and had longer procedural fluoroscopic times ( $p<0.05$ for all) (Table III).

The comparison of in-hospital major adverse events is summarised in Table IV.

None of the patients were lost to follow-up. In the matched population, the mean follow-up was

Table I. Baseline patient characteristics

\begin{tabular}{|c|c|c|c|c|c|c|}
\hline \multirow[t]{2}{*}{ Parameter } & \multicolumn{3}{|c|}{ Unmatched cohort } & \multicolumn{3}{|c|}{ Matched cohort } \\
\hline & $\begin{array}{c}\text { Double-vessel } \\
\text { disease } \\
\text { ( } n=244 \\
\text { patients) }\end{array}$ & $\begin{array}{l}\text { Single-vessel } \\
\text { disease } \\
\text { ( } n=375 \\
\text { patients) }\end{array}$ & $P$-value & $\begin{array}{c}\text { Double-vessel } \\
\text { disease } \\
\text { ( } n=226 \\
\text { patients) }\end{array}$ & $\begin{array}{l}\text { Single-vessel } \\
\text { disease } \\
\text { ( } n=226 \\
\text { patients) }\end{array}$ & $P$-value \\
\hline Age, mean \pm SD [years] & $69.6 \pm 7.6$ & $68.2 \pm 8.9$ & 0.076 & $69.1 \pm 7.6$ & $69.1 \pm 8.4$ & 0.779 \\
\hline Range & 46-89 & 24-91 & & 46-89 & 47-91 & \\
\hline Men & $68 \%$ & $62 \%$ & 0.122 & $67 \%$ & $67 \%$ & 1.000 \\
\hline Angina pectoris & $16 \%$ & $17 \%$ & 0.913 & $17 \%$ & $14 \%$ & 0.516 \\
\hline Dyspnoea, NYHA class > 1 & $33 \%$ & $35 \%$ & 0.665 & $33 \%$ & $34 \%$ & 1.000 \\
\hline $\begin{array}{l}\text { Previous myocardial } \\
\text { infarction }\end{array}$ & $31 \%$ & $25 \%$ & 0.140 & $28 \%$ & $27 \%$ & 0.833 \\
\hline Current smokers & $40 \%$ & $39 \%$ & 0.737 & $40 \%$ & $38 \%$ & 0.630 \\
\hline Hypertension & $94 \%$ & $89 \%$ & 0.034 & $93 \%$ & $90 \%$ & 0.235 \\
\hline $\begin{array}{l}\text { LDL-cholesterol } \\
\text { [mmol/l; mg/dl] }\end{array}$ & $\begin{array}{c}2.5 \pm 0.9 \\
96.8 \pm 34.8\end{array}$ & $\begin{array}{c}2.4 \pm 0.8 \\
92.9 \pm 30.9\end{array}$ & 0.165 & $\begin{array}{c}2.5 \pm 0.9 \\
96.8 \pm 34.8\end{array}$ & $\begin{array}{c}2.4 \pm 0.8 \\
92.9 \pm 30.9\end{array}$ & 0.110 \\
\hline $\begin{array}{l}\text { HDL-cholesterol } \\
\text { [mmol/l; mg/dl] }\end{array}$ & $\begin{array}{c}1.1 \pm 0.3 \\
42.6 \pm 11.6\end{array}$ & $\begin{array}{c}1.1 \pm 0.3 \\
42.6 \pm 11.6\end{array}$ & 0.957 & $\begin{array}{c}1.1 \pm 0.3 \\
42.6 \pm 11.6\end{array}$ & $\begin{array}{c}1.1 \pm 0.3 \\
42.6 \pm 11.6\end{array}$ & 0.792 \\
\hline $\begin{array}{l}\text { Plasma triglyceride } \\
{[\mathrm{mmol} / \mathrm{m} ; \mathrm{mg} / \mathrm{dl}]}\end{array}$ & $\begin{array}{c}1.8 \pm 1.0 \\
157.5 \pm 87.5\end{array}$ & $\begin{array}{c}1.8 \pm 1.1 \\
157.5 \pm 96.3\end{array}$ & 0.720 & $\begin{array}{c}1.8 \pm 1.1 \\
157.5 \pm 96.3\end{array}$ & $\begin{array}{c}1.8 \pm 1.0 \\
157.5 \pm 87.5\end{array}$ & 0.680 \\
\hline Diabetes mellitus & $41 \%$ & $42 \%$ & 0.802 & $40 \%$ & $40 \%$ & 1.000 \\
\hline Renal failure & $24 \%$ & $22 \%$ & 0.559 & $23 \%$ & $24 \%$ & 0.824 \\
\hline $\begin{array}{l}\text { Severe bronchopulmonary } \\
\text { disease }\end{array}$ & $14 \%$ & $12 \%$ & 0.538 & $14 \%$ & $12 \%$ & 0.678 \\
\hline Peripheral arterial disease & $40 \%$ & $35 \%$ & 0.173 & $39 \%$ & $32 \%$ & 0.141 \\
\hline Ejection fraction < $40 \%$ & $12 \%$ & $9 \%$ & 0.345 & $12 \%$ & $12 \%$ & 1.000 \\
\hline $\begin{array}{l}\text { History of coronary artery } \\
\text { bypass grafting }\end{array}$ & $16 \%$ & $19 \%$ & 0.332 & $15 \%$ & $17 \%$ & 0.521 \\
\hline $\begin{array}{l}\text { Need of open-heart surgery } \\
\text { within } 30 \text { days }\end{array}$ & $11 \%$ & $9 \%$ & 0.405 & $11 \%$ & $9 \%$ & 0.641 \\
\hline $\begin{array}{l}\text { Previous coronary artery } \\
\text { intervention }\end{array}$ & $30 \%$ & $32 \%$ & 0.535 & $31 \%$ & $28 \%$ & 0.605 \\
\hline $\begin{array}{l}\text { Known multivessel coronary } \\
\text { artery disease }\end{array}$ & $38 \%$ & $42 \%$ & 0.315 & $37 \%$ & $40 \%$ & 0.562 \\
\hline Previous stroke & $37 \%$ & $32 \%$ & 0.222 & $36 \%$ & $33 \%$ & 0.552 \\
\hline
\end{tabular}


Table II. Medication prior to stenting

\begin{tabular}{|lcccccc|}
\hline Medication & \multicolumn{3}{c}{ Unmatched cohort } & \multicolumn{3}{c|}{ Matched cohort } \\
\cline { 2 - 8 } & $\begin{array}{c}\text { Double-vessel } \\
\text { disease } \\
(n=244 \\
\text { patients })\end{array}$ & $\begin{array}{c}\text { Single-vessel } \\
\text { disease } \\
(n=355 \\
\text { patients })\end{array}$ & $P$-value & $\begin{array}{c}\text { Double-vessel } \\
\text { disease } \\
(n=226 \\
\text { patients })\end{array}$ & $\begin{array}{c}\text { Single-vessel } \\
\text { disease } \\
(n=226 \\
\text { patients })\end{array}$ \\
\hline Aspirin & $85 \%$ & $83 \%$ & 0.579 & $85 \%$ & $82 \%$ & 0.525 \\
\hline Clopidogrel & $39 \%$ & $42 \%$ & 0.454 & $40 \%$ & $42 \%$ & 0.848 \\
\hline Statin & $76 \%$ & $80 \%$ & 0.370 & $76 \%$ & $81 \%$ & 0.252 \\
\hline ACE inhibitor & $73 \%$ & $74 \%$ & 0.926 & $74 \%$ & $78 \%$ & 0.379 \\
\hline Beta-blocker & $60 \%$ & $62 \%$ & 0.673 & $60 \%$ & $57 \%$ & 0.633 \\
\hline
\end{tabular}

Table III. Interventional and angiographic characteristics

\begin{tabular}{|c|c|c|c|c|c|c|}
\hline \multirow[t]{2}{*}{ Parameter } & \multicolumn{3}{|c|}{ Unmatched cohort } & \multicolumn{3}{|c|}{ Matched cohort } \\
\hline & $\begin{array}{c}\text { Double-vessel } \\
\text { disease } \\
(n=244 \\
\text { patients } \\
367 \text { proce- } \\
\text { dures) }\end{array}$ & $\begin{array}{l}\text { Single-vessel } \\
\text { disease } \\
\text { ( } n=355 \\
\text { patients } \\
396 \text { proce- } \\
\text { dures) }\end{array}$ & $P$-value & $\begin{array}{l}\text { Double-vessel } \\
\text { disease } \\
\text { ( } n=226 \\
\text { patients; } \\
343 \text { proce- } \\
\text { dures) }\end{array}$ & $\begin{array}{l}\text { Single-vessel } \\
\text { disease } \\
\text { ( } n=226 \\
\text { patients; } \\
236 \text { proce- } \\
\text { dures) }\end{array}$ & $P$-value \\
\hline $\begin{array}{l}\text { Lesion located in LICA/ } \\
\text { RICA }\end{array}$ & $53 \% / 47 \%$ & $53 \% / 47 \%$ & 1.000 & $53 \% / 47 \%$ & $51 \% / 49 \%$ & 0.555 \\
\hline Stenosis 90-99\% & $40 \%$ & $43 \%$ & 0.339 & $39 \%$ & $43 \%$ & 0.390 \\
\hline Ostial ICA lesion & $71 \%$ & $67 \%$ & 0.310 & $71 \%$ & $64 \%$ & 0.084 \\
\hline Stenosis at baseline & $82.4 \pm 9.5$ & $83.2 \pm 10.3$ & 0.188 & $82.4 \pm 9.4$ & $83.0 \pm 10.5$ & 0.308 \\
\hline Residual stenosis & $11.3 \pm 12.1$ & $9.8 \pm 11.7$ & 0.034 & $11.4 \pm 12.0$ & $10.2 \pm 10.6$ & 0.272 \\
\hline Contrast medium [ml] & $122 \pm 42$ & $115 \pm 43$ & 0.012 & $121 \pm 43$ & $114 \pm 44$ & 0.021 \\
\hline $\begin{array}{l}\text { Mean stent length } \\
{[\mathrm{mm}]}\end{array}$ & $35 \pm 14$ & $37 \pm 12$ & 0.033 & $35 \pm 14$ & $37 \pm 11$ & 0.045 \\
\hline $\begin{array}{l}\text { Atropine during } \\
\text { procedure }\end{array}$ & $49 \%$ & $51 \%$ & 0.612 & $48 \%$ & $48 \%$ & 0.866 \\
\hline $\begin{array}{l}\text { Number } \\
\text { of post-dilations }\end{array}$ & $1.1 \pm 0.7$ & $1.1 \pm 0.6$ & 0.768 & $1.1 \pm 0.7$ & $1.0 \pm 0.5$ & 0.862 \\
\hline $\begin{array}{l}\text { Fluoroscopic time, } \\
\text { median (IQR) [min] }\end{array}$ & $7.0(5.3 ; 9.9)$ & $6.1(5.0 ; 9.0)$ & 0.015 & $7.0(5.3 ; 9.9)$ & $6.2(4.5 ; 9.2)$ & 0.046 \\
\hline
\end{tabular}

Table IV. In-hospital major adverse events

\begin{tabular}{|c|c|c|c|c|c|c|}
\hline \multirow[t]{2}{*}{ Parameter } & \multicolumn{3}{|c|}{ Unmatched cohort } & \multicolumn{3}{|c|}{ Matched cohort } \\
\hline & $\begin{array}{c}\text { Double-vessel } \\
\text { disease } \\
\text { ( } n=244 \\
\text { patients) }\end{array}$ & $\begin{array}{c}\text { Single-vessel } \\
\text { disease } \\
(n=355 \\
\text { patients) }\end{array}$ & $P$-value & $\begin{array}{c}\text { Double-vessel } \\
\text { disease } \\
\text { ( } n=226 \\
\text { patients) }\end{array}$ & $\begin{array}{c}\text { Single-vessel } \\
\text { disease } \\
\text { ( } n=226 \\
\text { patients) }\end{array}$ & $P$-value \\
\hline Minor stroke, $n(\%)$ & $6(2.5)$ & $6(1.6)$ & 0.554 & $6(2.7)$ & $4(1.8)$ & 0.751 \\
\hline Major stroke, $n$ (\%) & $1(0.4)$ & $6(1.6)$ & 0.254 & $1(0.4)$ & $3(1.3)$ & 0.623 \\
\hline $\begin{array}{l}\text { Myocardial infarction, } \\
n(\%)\end{array}$ & $1(0.4)$ & 0 & 0.394 & $1(0.4)$ & $1(0.4)$ & 1.000 \\
\hline Death, $n(\%)$ & $2(0.8)$ & $2(0.5)$ & 1.000 & $1(0.4)$ & 0 & 1.000 \\
\hline $\begin{array}{l}\text { Patients with one or } \\
\text { more major adverse } \\
\text { events, } n(\%)\end{array}$ & $9(3.7)$ & $12(3.2)$ & 0.821 & $8(3.5)$ & $7(3.1)$ & 1.000 \\
\hline
\end{tabular}




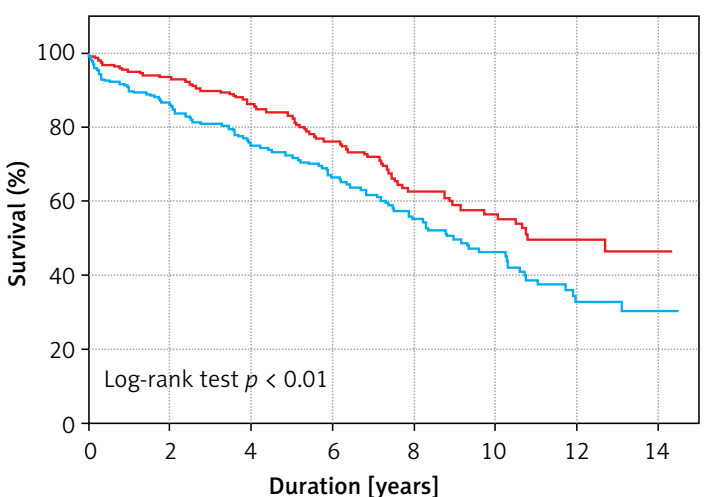

No. at risk:

$\begin{array}{llllllll}226 & 194 & 153 & 112 & 70 & 47 & 21 & 6 \\ 226 & 186 & 148 & 107 & 74 & 48 & 22 & 6\end{array}$

ـ Single-carotid disease —ـ Double-carotid disease

Figure 1. Kaplan-Meier survival curves describing freedom of all-cause mortality in single- versus double-vessel carotid disease in patients after an index carotid artery stenting

$6.1 \pm 4.0$ years, and a total of 181 (40\%) deaths occurred during 2759 patient-years, which translates into 7.8 and 5.3 deaths per 100 patient-years in the double-vessel carotid group and the single-vessel carotid group, respectively $(p<0.01)$. Survival in the double-vessel carotid group vs. the single-vessel-carotid group at 5 and 10 years was $72 \%$ (95\% confidence interval $(\mathrm{Cl}): 66-78 \%)$ vs. $83 \%(95 \% \mathrm{Cl}: 77-87 \%)$, and $46 \%(95 \% \mathrm{Cl}$ : $38-54 \%)$ vs. $55 \%(95 \% \mathrm{Cl}: 47-63 \%)$, respectively (log rank $p<0.01)$. The Kaplan-Meier curves of allcause death are shown in Figure 1.

Twenty-four (11\%) patients and 6 (3\%) patients underwent re-interventions for restenosis in the double-vessel and the single-vessel carotid disease groups, respectively $(p<0.01)$ (Figure 2$)$.

\section{Discussion}

To our knowledge, this study is the first evaluating the long-term survival of carotid artery stenting patients with regard to significant unilateral or bilateral carotid stenosis assessed by angiography. This study, using propensity score matching analysis, was designed to test our hypothesis that patients with significant atherosclerosis that affects both carotid arteries have worse long-term survival. Here, we report the following essential findings: (1) the long-term survival of patients with double-vessel carotid disease treated with carotid artery stenting was significantly worse than that of patients with single-vessel carotid disease; (2) patients in both matched groups had a high annual mortality rate; (3) the occurrence of in-hospital major adverse events was similar in both groups of the matched patients; and (4) patients in the double-vessel

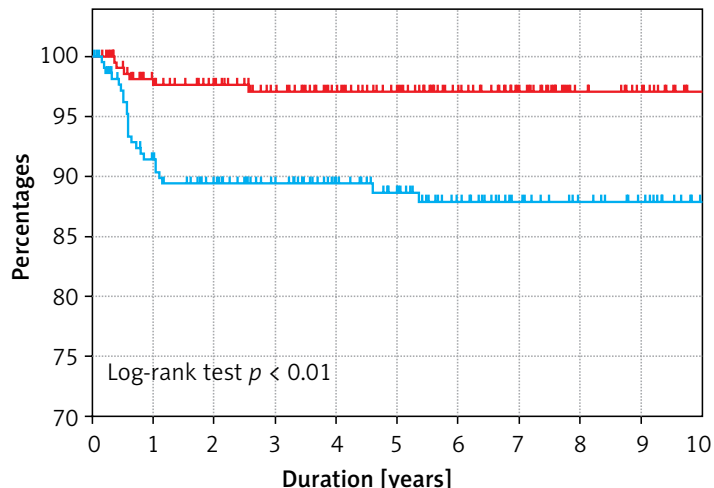

No. at risk:

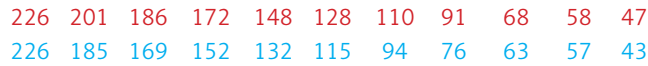

ـ Single-carotid disease — Double-carotid disease

Figure 2. Kaplan-Meier survival curves describing freedom of re-intervention for restenosis in singleversus double-vessel carotid disease in patients after an index carotid artery stenting

carotid group underwent more frequent re-interventions for restenosis.

The concept that more severe atherosclerosis is associated with a worse prognosis, has been known for decades. It found its first application in coronary arteries, with the subsequent emergence of a classification showing different prognoses in the natural course of coronary artery disease in patients with single versus multi-vessel disease $[1,10]$. The same concept was applied later, only in a more sophisticated way, helping in the creation of a SYNTAX Score. The SYNTAX Score is a tool that evaluates the complexity of coronary artery disease, in which patients with a higher score have a worse course of coronary artery disease and worse long-term prognosis [11]. With continuous development of non-invasive cardiovascular examinations, the same concept was introduced into clinical algorithms using CT angiography and/ or duplex ultrasound. Several studies have confirmed the basic paradigm that more severe atherosclerosis in more arterial territories is associated with a worse cardiovascular prognosis [12,13].

In line with the same concept, we demonstrate that patients suffering from extensive carotid disease are at high risk of death and should be further clinically stratified. In such patients, the main focus should be placed on aggressive conservative treatment including the use of statins and antithrombotic medication, as well as use of antihypertensive and antidiabetic medication if necessary. Additionally, life-style modifications with smoking cessation and maintaining regular physical activity are of crucial importance. Notably, the majority of patients in the presented cohort had a high cardiovascular risk, which resulted in an estimated 10-year allcause mortality rate of approximately $50 \%$. 
Interestingly, the all-cause mortality rate in this study was much higher than was demonstrated in the long-term follow-up of two recent and important randomised studies comparing CAS and endarterectomy (CREST study: CAS patients, $n=$ 1262 ; 10 -year risk of death or stroke $\approx 11 \%$; ACT 1 study: CAS patients, $n=1809$, 5-year mortality rate $\approx 13 \%)[14,15]$. On the other hand, the patients' characteristics in "real-world" registries show greater risk, which translates into higher long-term mortality rates (Columbo et al.: CAS patients, $n=4415,5$-year mortality rate $\approx 18 \%$; Mudra et al., CAS patients, $n=878$, median follow-up 5.5 years, mortality rate $=33 \%$ ) $[16,17]$. These differences suggest that controlled clinical trials may under-represent groups of high-risk patients in whom the investigated technique is used in daily clinical practice, and therefore we should carefully stratify our patients to more objectively assess their long-term prognosis.

A series of patients with carotid artery restenosis, examined by intravascular ultrasound and near-infrared spectroscopy, showed that early restenosis is mainly caused by neointimal hyperplasia and/or an insufficient stent expansion [18]. On the other hand, late restenosis occurring years after the index procedure is often caused by neoatherosclerosis, which histologically resembles the primary atherosclerotic plaque $[18,19]$. In this study, reinterventions for restenosis were mostly performed in the first year. Thus, we can speculate that neointimal hyperplasia or insufficient final results of the primary CAS might be a probable factor leading to the higher occurrence of early restenosis. Similarly, Tekieli et al. identified bilateral carotid disease as an independent risk factor of restenosis [20], and Wasser et al. showed contralateral carotid artery occlusion as a strong independent predictor of in-stent restenosis (hazard ratio $\approx 10$ ) [21].

This study has several limitations. First, because the data were collected in a single centre, the results cannot be generalised in a simple manner. Second, propensity matching estimates an average effect from observational data, which is associated with many inherent limitations. However, in the context of studies performed in other vascular territories it seems to be highly probable that significant double-vessel carotid disease is an important marker of unfavourable prognosis. Third, we did not analyse causes of death in the studied cohort of patients.

In conclusion, patients with CAS and significant double-vessel carotid disease had similar peri-procedural risk but had a worse long-term survival and a higher rate of re-interventions for restenosis compared to the single-vessel carotid artery disease patients.

\section{Acknowledgments}

The authors are grateful to Dr. Jiri Jarkovsky for his assistance with statistical analysis.

\section{Conflict of interest}

The authors declare no conflict of interest.

\section{References}

1. Burggraf GW, Parker JO. Prognosis in coronary artery disease: angiographic, hemodynamic and clinical factors. Circulation 1975; 31: 146-56.

2. Veselka J, Zimolová P, Špaček M, et al. Comparison of carotid artery stenting in patients with single versus bilateral carotid artery disease and factors affecting midterm outcome. Ann Vasc Surg 2011; 25: 796-804.

3. Veselka J, Černá D, Zimolová P, et al. Thirty-day outcome of direct carotid stenting with cerebral protection in high-risk patients. Circ J 2007; 71: 1468-72.

4. Štěchovský C, Hájek P, Horváth M, et al. Near-infrared spectroscopy combined with intravascular ultrasound in carotid arteries. Int J Cardiovasc Imag 2016; 32: 181-8.

5. Štěchovský C, Hájek P, Horváth M, Veselka J. Effect of stenting on the near-infrared spectroscopy-derived lipid core burden index of carotid artery plaque. Eurolntervention 2019; 12: e289-96.

6. Artas H, Okcesiz I. Three-dimensional ultrasonographic evaluation of carotid artery plaque surface irregularity. Arch Med Sci 2019; 16: 58-65.

7. Naylor AR, Ricco JB, de Borst GJ, et al. Management of atherosclerotic carotid and vertebral artery disease: 2017 Clinical practice guidelines of the European Society for Vascular surgery (ESVS). Eur J Vasc Endovasc Surg 2018; 55: 3-81.

8. Aboyans V, Ricco JB, Bartelink MEL, et al. 2017 ESC Guidelines on the Diagnosis and Treatment of Peripheral Arterial Diseases, in collaboration with the European Society for Vascular Surgery (ESVS): Document covering atherosclerotic disease of extracranial carotid and vertebral, mesenteric, renal, upper and lower extremity arteries Endorsed by: the European Stroke Organization (ESO)The Task Force for the Diagnosis and Treatment of Peripheral Arterial Diseases of the European Society of Cardiology (ESC) and of the European Society for Vascular Surgery (ESVS). Eur Heart J 2018; 39: 763-816.

9. Bates ER, Babb JD, Casey DE, et al. ACCF/SCAl/SVMB/ SIR/ASITN 2007 clinical expert consensus document on carotid stenting. J Am Coll Cardiol 2007; 49: 126-70.

10. Harris PJ, Harrel FE, Lee KL, Behar VS, Rosati RA. Survival in medically treated coronary artery disease. Circulation 1979; 60: 1259-69.

11. Tam DY, Bakaeen F, Feldman DN, et al. Modality selection for the revascularization of left main disease. Can J Cardiol 2019; 35: 983-92.

12. Calais F, Ostman ME, Hedberg P, Rosenblad A, Leppert J, Frobert $\mathrm{O}$. Incremental prognostic value of coronary and systemic atherosclerosis after myocardial infarction. Int J Cardiol 2018; 261: 6-11.

13. Cappeletti A, Astore D, Godino C, et al. Relationship between Syntax Score and prognostic localization of coronary artery lesions with conventional risk factors, plasma profile markers, and carotid atherosclerosis (CAPP Study 2). Int J Cardiol 2018; 257: 306-11. 
14. Brott TG, Howard G, Roubin GS, et al. Long-term results of stenting versus endarterectomy for carotid-artery stenosis. N Engl J Med 2016; 374: 1021-31.

15. Rosenfield K, Matsumura JS, Chatuverdi S, et al. Randomized trial of stent versus surgery for asymptomatic carotid stenosis. N Engl J Med 2016; 374: 1011-20.

16. Columbo JA, Martinez-Camblor P, MacKenzie TA, et al. A comparative analysis of long-term mortality after carotid endarterectomy and carotid stenting. J Vasc Surg 2019; 69: 104-9.

17. Mudra H, Staubach S, Hein-Rothweiler R, et al. Longterm outcomes of carotid artery stenting in clinical practice. Circ Cardiovasc Interv 2016; 9: e003940.

18. Štěchovský C, Hájek P, Horváth M, Špaček M, Veselka J. Composition of carotid artery stenosis and restenosis: A series of patients assessed with intravascular ultrasound and near-infrared spectroscopy. Int I Cardiol 2016; 207: 64-6.

19. Hellings WE, Moll Fl, de Vries JP, de Kleijn DP, Pasterkamp G. Histological characterization of restenotic carotid plaque in relation to recurrence interval and clinical presentation: a cohort study. Stroke 2008; 39: 1029-32.

20. Tekieli L, Musialek P, Kablak-Ziembicka A, et al. Severe, recurrent in-stent carotid restenosis: endovascular approach, risk factors. Results from a prospective academic registry of 2637 consecutive carotid artery stenting procedures (TARGET-CAS). Adv Interv Cardiol 2019; 15: 465-71.

21. Wasser K, Schnaudigel S, Wohlfart J, et al. Clinical impact and predictors of carotid in-stent restenosis. J Neurol 2012; 259: 1896-902. 